\title{
Skip metastasis in papillary thyroid carcinoma is difficult to predict in clinical practice
}

\author{
Xilin Nie, Zhou Tan and Minghua Ge*
}

\begin{abstract}
Background: Cervical lymph node metastases are very common in papillary thyroid cancer (PTC), and typically spread in a predictable stepwise fashion in clinical practice. However, lateral lymph node metastasis (LLNM) without central lymph node metastasis (CLNM) as skip metastasis is not rare in PTC. The aim of this study was to investigate the incidence, risk factors and pattern of skip metastasis in PTC.

Methods: A total of 271 patients with PTC and suspicious LLN diagnosed by pre-operation examinations who underwent total thyroidectomy and central lymph node dissection plus lateral lymph node dissection between January 2008 and December 2011 were enrolled in this study. Clinicopathological features were collected, and the pattern of cervical lymph node metastasis and skip metastasis were analyzed.

Results: The LLNM rate was $74.9 \%$ (203/271, diagnosed by postoperative pathology examination) and significantly associated with extrathyroid extension (ETE), primary tumor located at the upper pole, and CLNM $(p<0.05)$. The skip metastasis rate was $14.8 \%$ (30/203) and was more frequently found in microcarcinoma patients, especially when the primary tumor size was $\leq 0.5 \mathrm{~cm}(p=0.001 \mathrm{OR}=12.9)$. However, skip metastasis was unrelated to the remaining factors examined.

Conclusion: Small cancers with a pre-operation diagnosis of LLNM are more likely to have skip metastases, especially when the primary tumor size is less than $0.5 \mathrm{~cm}$ in diameter; however, this type of metastasis appears to develop in a random fashion. Thus, additional research is needed to identify potential predictive factors, such as a primary tumor located at the upper pole.
\end{abstract}

Keywords: Papillary thyroid carcinoma, Skip metastasis, Lateral lymph node metastasis, Central lymph node metastasis, Risk factors

\section{Background}

Papillary thyroid carcinoma (PTC) accounts for approximately $80.0 \%$ of all thyroid malignancies and generally grows slowly. Thus, as an indolent disease, the prognosis is good for the majority of patients $[1,2]$. However, cervical lymph node metastasis very common in PTC and is associated with an increased risk of local regional recurrence and overall mortality in select patient populations, although it does not show a major effect on prognosis [3-5]. As a result, controlling loco-regional recurrence has become a major challenge for most thyroid surgeons [6].

\footnotetext{
* Correspondence: gemh@zjcc.org.cn

Department of Head and Neck Surgery, Zhejiang Cancer Hospital, No.1 East Banshan Road, Hangzhou 310022, People's Republic of China
}

Many previous studies have reported that the dissemination of PTC cells through the lymphatic system occurs in a largely predictable stepwise fashion [7, 8]. Lymph node metastasis in PTC involves the central compartment first, followed by the ipsilateral lateral compartment and then the contralateral lateral compartment and the mediastinal lymph nodes $[9,10]$. However, some patients develop lateral lymph node metastasis (LLNM) in PTC without central lymph node metastasis (CLNM); in these cases, a skip metastasis is noted as positive metastasis to the lateral lymph nodes without the involvement of the central lymph nodes. The frequency of skip metastasis in PTC is approximately 0.6$37.5 \%[6,8,11-24]$; however, these estimates come from 
studies that were limited by low patient numbers and that included primary and recurrent patients in their study population. In addition, although a few studies have assessed the risk factors for skip metastasis in PTC, prospective clinical trials were lacking [25]; preventing determination the intrinsic characteristics of skip metastasis. The aim of the present study was to investigate the incidence, pattern and risk factors of skip metastasis in PTC patients. We retrospectively analyzed clinical data from patients in our hospital who were treated with systematic therapeutic lateral neck dissection.

\section{Methods}

The study was approved by the Institutional Review Board of Zhejiang Cancer Hospital, and formal consent was not required for this research. We retrospectively reviewed the clinical records of 271 patients with PTC and suspicious LLNM diagnosed by pre-operation examinations who underwent total thyroidectomy and central lymph node dissection plus lateral lymph node dissection between January 2008 and December 2011. These patients received their first treatment in the Department of Head and Neck Surgery, Zhejiang Cancer Hospital. All cases were diagnosed with PTC with LLNM by general pathology examination in the department of pathology of our hospital. Patients with other types of thyroid malignancy or with high risk cell types of PTC (e.g., tall cell variant, hobnail variant), with tumors in the isthmus or a family history of PTC were excluded. Patients with a history of neck surgery for other diseases or radiation exposure were also excluded. If the treatment was a palliative surgery, these patients were also excluded.

All patients received a physical examination (PE), ultrasonic examination (US) of the thyroid gland and neck lymph nodes, and neck and thorax computer tomography (CT) with contrast. Fine needle aspiration was not systematically performed in our hospital at the time of this study.The criteria for metastasis requiring US were as follows: round shape (long/short ratio < 2), microcalcification, cystic change, hyperechogenicity and heterogeneous inner structure [26]. The criteria for CT were as follows: enhancement, heterogeneous, cystic or necrotic change and round shape. The size criteria for both US and $\mathrm{CT}$ were based on an upper limit of $15 \mathrm{~mm}$ for the nodal diameter of the normal long axis in cases of jugulodigastric and submandibular nodes and $10 \mathrm{~mm}$ for all other cervical nodes except for level VI [27].

The initial surgical procedure in our institution was either a bilateral procedure (near-total or total thyroidectomy) or a unilateral procedure (lobectomy) plus bilateral or ipsilateral central compartment dissection. Lateral lymph node dissection was performed if the patient satisfied at least one of the selection criteria; for example, if there was a positive or suspicious preoperative radiographic finding in the lateral lymph nodes, or if multiple metastatic lateral lymph nodes were identified from the intraoperative frozen biopsy. In this study, all patients underwent total thyroidectomy and therapeutic lateral neck dissection that included levels II to $\mathrm{V}$ [28]. Level I was dissected only if there were radiographic, cytopathologic, or intraoperative findings suggestive of metastatic cancer. No patients underwent level I dissection in our study.

The clinical data were retrospectively analyzed with respect to gender, age, tumor size, tumor spread, presence of psammoma bodies, tumor multifocality, extrathyroidal extension (ETE), primary tumor location, CLNM, and LLNM. When multiple lesions were found in the specimen, the largest tumor or the most suspicious dominant nodule was analyzed.

All statistical analyses were two-sided and performed using the Statistical Package for Social Sciences (SPSS, Inc., Chicago, IL, USA). Univariate analyses were performed using the chi-square test and Fisher's exact test. Data not exhibiting a normal distribution were tested using the Mann-Whitney $\mathrm{U}$ test. Variables with $p<0.1$ in the univariate analyses were included in the multivariate analyses. The multivariate analyses were performed using binary logistic regression analysis to estimate the odds ratios (OR) of individual parameters. The results are presented as ORs with 95\% confidence intervals (CI) and $p$ values. Some variables were regrouped according to the TNM staging of the tumor according to the American Joint Committee on Cancer (AJCC)/Union for International Cancer Control (UICC) classification system for further binary logistic regression analysis as follows: age $\leq 45$ vs. $>45$ years and tumor location superior vs. elsewhere [29]. For the 6 age categories, 5 dummy variables were introduced, and the first category was selected as the reference category. For the 5 size categories, 4 dummy variables were introduced, and the last category was selected as the reference category. For the 3 capsular invasion categories, 2 dummy variables were introduced, and the first category was selected as the reference category. For the 4 location categories, 3 dummy variables were introduced, and the last category was selected as the reference category. Any $p$ value (two-tailed tests) less than 0.05 was considered statistically significant.

\section{Results}

\section{Demographics of all enrolled patients}

In this study, 271 patients were enrolled. There were 64 males and 207 females, representing a male: female ratio of 1:3.23. The age of the patients ranged from 12 to 85 years with a median age of 44.80 years. Tumor diameter ranged from 0.1 to $6.0 \mathrm{~cm}$ with a median diameter of $1.5 \mathrm{~cm}$. Among all patients, 47 showed tumor spread 
in the thyroid gland. A total of 86 patients exhibited ETE, and 31 patients exhibited multifocality in one thyroid lobe. In $75.3 \%$ of patients, the primary tumor was located in the upper two-thirds of the lobe (with 107 tumors in the upper part and 97 tumors in the middle) (Table 1). CLNM was present in 191 patients (70.5\%), and LLNM was present in 203 patients (74.9\%) after post-operative pathological examinations. In this study, a total of 261 patients received total thyroidectomy with bilateral or ipsilateral central compartment dissection plus ipsilateral lateral lymph node dissection, and 10

Table 1 Clinicopathologicial features of all 271 enrolled patients and univariate analyses results (271 patients)

\begin{tabular}{|c|c|c|c|c|c|}
\hline Characteristics & & $\begin{array}{l}\text { LLNM } \\
\text { negative }\end{array}$ & $\begin{array}{l}\text { LLNM } \\
\text { positive }\end{array}$ & Total & $\begin{array}{l}\text { Univariate } \\
\text { analysis } \\
p \text {-value }\end{array}$ \\
\hline \multirow[t]{2}{*}{ Gender } & Female & 55 & 152 & 207 & 0.313 \\
\hline & Male & 13 & 51 & 64 & \\
\hline \multirow[t]{6}{*}{ Age(year) } & $\leq 25$ & 2 & 19 & 21 & 0.087 \\
\hline & $25-35$ & 8 & 41 & 49 & \\
\hline & $35-45$ & 20 & 64 & 84 & \\
\hline & $45-55$ & 20 & 49 & 69 & \\
\hline & $55-65$ & 10 & 19 & 29 & \\
\hline & $>65$ & 8 & 11 & 19 & \\
\hline \multirow[t]{2}{*}{ Age(year) } & $\leq 45$ & 30 & 124 & 154 & $0.014^{*}$ \\
\hline & $>45$ & 38 & 79 & 117 & \\
\hline \multirow[t]{5}{*}{ Size (cm) } & $\leq 0.5$ & 15 & 10 & 25 & $0.000^{*}$ \\
\hline & $0.5-1$ & 21 & 44 & 65 & \\
\hline & $1-1.5$ & 12 & 40 & 52 & \\
\hline & $1.5-2$ & 8 & 32 & 40 & \\
\hline & $>2$ & 12 & 77 & 89 & \\
\hline \multirow[t]{2}{*}{ Tumor Spread } & Absent & 65 & 159 & 224 & $0.001^{*}$ \\
\hline & Present & 3 & 44 & 47 & \\
\hline \multirow[t]{2}{*}{ Psammoma bodies } & Absent & 66 & 195 & 261 & 1 \\
\hline & Present & 2 & 8 & 10 & \\
\hline \multirow[t]{2}{*}{ Multifocality } & Single & 61 & 179 & 240 & 0.732 \\
\hline & Multi & 7 & 24 & 31 & \\
\hline \multirow[t]{2}{*}{ ETE } & None & 58 & 127 & 185 & $0.000^{*}$ \\
\hline & ETE & 10 & 76 & 86 & \\
\hline \multirow[t]{4}{*}{ Location } & Upper & 8 & 99 & 107 & $0.000^{*}$ \\
\hline & Middle & 34 & 63 & 97 & \\
\hline & Inferior & 23 & 20 & 43 & \\
\hline & Whole & 3 & 21 & 24 & \\
\hline \multirow[t]{2}{*}{ Location Upper } & Upper & 8 & 99 & 107 & $0.000^{*}$ \\
\hline & None & 60 & 104 & 164 & \\
\hline \multirow[t]{2}{*}{ CLNM } & Absent & 50 & 30 & 80 & $0.000^{*}$ \\
\hline & Present & 18 & 173 & 191 & \\
\hline
\end{tabular}

*symbol for $p<0.05$; ETE extrathyroid extension, CLNM central lymph node metastases, LLNM lateral lymph node metastasis patients received total thyroidectomy with bilateral central compartment dissection plus bilateral lateral lymph node dissection.

In the univariate analyses, LLNM was significantly associated with age, size, tumor spread, ETE, primary tumor location and CLNM $(p<0.05)$, whereas no significant association was found between LLNM and gender, presence of psammoma bodies, multifocality $(p>0.05)$ (Table 1).

The multivariate analysis results are shown in Table 2 . The risk factors correctly predicted $86.7 \%$ of patients with LLNM. In the multivariate analyses, LLNM was significantly associated with ETE, primary tumor location in the upper part of the thyroid lobe, and a positive finding for CLNM (Table 2).

\section{Prevalence of skip metastasis}

In those 203 patients with LLNM, 44 patients showed tumor spread in the thyroid gland, 76 patients exhibited ETE, and 24 patients exhibited multifocality in one thyroid lobe. Additionally, 173 (85.2\%) patients presented with CLNM, and 30 (14.8\%) patients demonstrated skip metastasis as LLNM without CLNM (Table 3).

The 30 patients, $80.0 \%$ were female, $50.0 \%$ were older than 45 years, and only $10.0 \%$ demonstrated tumor spread in the thyroid lobe, with the location of the primary tumor in the upper part of the thyroid lobe in $63.3 \%$ of patients. In the univariate analyses, skip metastasis was associated only with tumor size (Table 4).

For the multivariate analysis, a binary logistic regression was performed, and the results showed that patients with a tumor size $\leq 0.5 \mathrm{~cm}$ had a significantly higher frequency of skip metastasis than did patients with a tumor size larger than $0.5 \mathrm{~cm}$ (Table 5).

\section{Discussion}

Cervical lymph node metastasis is very common in PTC with an occurrence rate of approximately $18.0-90.0 \%$ [2, $3,30,31]$. Although it remains debated whether lymph node metastasis in patients with PTC is associated with a poor prognosis, there is a consensus that lymph node metastasis at diagnosis can increase the risk of lymph node recurrence, and that re-operation for disease recurrence in the cervical nodes may increase operative complications and medical costs [32, 33].

In this study, the LLNM rate was $74.9 \%(203 / 271)$, which is in agreement with previous reports $[2,3,31]$. However, this rate is much higher than that the $20.0 \%$ reported by Patron V, for lateral compartment metastasis in cN0 patients with PTC who had undergone total thyroidectomy and therapeutic lateral neck dissection [34]. In the present study, all patients were suspected $\mathrm{cN}_{+}$, based on radiographic, cytopathologic, intraoperative findings suggestive of metastasis. As a result, therapeutic 
Table 2 Multivariate logistic regression results for LLNM (271 patients)

\begin{tabular}{lllll}
\hline Predictive factor & $p$ & OR & \multicolumn{2}{c}{ 95\% C.I. of OR } \\
\cline { 5 - 6 } & & & Lower & Upper \\
\hline ETE(absent versus present) & $0.026^{*}$ & 2.756 & 1.132 & 6.715 \\
Location(none versus upper) & $0.000^{*}$ & 10.471 & 4.052 & 27.062 \\
CLNM(absent versus present) & $0.000^{*}$ & 20.846 & 9.505 & 45.720 \\
\hline
\end{tabular}

*symbol for $p<0.05$; ETE extrathyroid extension, CLNM central lymph node metastases, LLNM lateral lymph node metastasis

Table 3 Demographics of 203 patients with lateral compartment metastasis positive (203 patients)

\begin{tabular}{|c|c|c|c|}
\hline Characteristics & & $\begin{array}{l}\text { Number of } \\
\text { patients }\end{array}$ & Percentage(\%) \\
\hline \multirow[t]{2}{*}{ Gender } & Female & 152 & 74.88 \\
\hline & Male & 51 & 25.12 \\
\hline \multirow[t]{6}{*}{ Age(year) } & $\leq 25$ & 19 & 9.36 \\
\hline & $25-35$ & 41 & 20.20 \\
\hline & $35-45$ & 64 & 31.53 \\
\hline & $45-55$ & 49 & 24.14 \\
\hline & $55-65$ & 19 & 9.36 \\
\hline & $>65$ & 11 & 5.42 \\
\hline \multirow[t]{2}{*}{ Age(year) } & $\leq 45$ & 124 & 61.08 \\
\hline & $>45$ & 79 & 38.92 \\
\hline \multirow[t]{5}{*}{ Size $(\mathrm{cm})$} & $\leq 0.5$ & 10 & 4.93 \\
\hline & $0.5-1$ & 44 & 21.67 \\
\hline & $1-1.5$ & 40 & 19.70 \\
\hline & $1.5-2$ & 32 & 15.76 \\
\hline & $>2$ & 77 & 37.93 \\
\hline \multirow[t]{2}{*}{ Tumor Spread } & Absent & 159 & 78.33 \\
\hline & Present & 44 & 21.67 \\
\hline \multirow[t]{2}{*}{ Psammoma bodies } & Absent & 195 & 96.60 \\
\hline & Present & 8 & 3.40 \\
\hline \multirow[t]{2}{*}{ Multifocality } & Single & 179 & 88.18 \\
\hline & Multi & 24 & 11.82 \\
\hline \multirow[t]{2}{*}{ ETE } & None & 127 & 62.56 \\
\hline & ETE & 76 & 37.44 \\
\hline \multirow[t]{4}{*}{ Location } & Upper & 99 & 48.77 \\
\hline & Middle & 63 & 31.03 \\
\hline & Inferior & 20 & 9.85 \\
\hline & Whole & 21 & 10.34 \\
\hline \multirow[t]{2}{*}{ Location Upper } & Upper & 99 & 48.77 \\
\hline & None & 104 & 51.23 \\
\hline \multirow[t]{2}{*}{ CLNM } & Absent & 30 & 14.78 \\
\hline & Present & 173 & 85.22 \\
\hline
\end{tabular}

ETE extrathyroid extension, CLNM central lymph node metastases, LLNM lateral lymph node metastasis lateral neck dissection was performed, which might explain the higher LLNM rate observed here than that found in the study by Patron V. Nonetheless, in the present study, $25.1 \%$ of the patients did not demonstrate LLNM. All patients received PE, US and contrasted CT examination preoperatively, although fine needle aspiration examination was not systematically performed in our hospital at the time of the study. In recent clinical work, an increasing number of patients have received the fine needle aspiration examination for suspiciously lateral lymph nodes, follow by TG examination if the aspiration results were indeterminate. By performing these evaluation, many unnecessary neck dissections can be avoided.

In previous studies, in which a palpable lateral lymph node was considered a metastatic lymph node, the falsepositive rate and false-negative rate were both in the range of $20.0-30.0 \%$ [35]. The US/CT combination was superior to US alone in the detection of metastatic lymph nodes at lateral neck levels, which is consistent with other studies [36]. In the present research, if any suspicious radiographic findings were discovered (CT and US), neck dissection was conducted with or without fine needle aspiration examination in our clinic. Of the $41(15.1 \%, 41 / 271)$ patients who received fine needle aspiration examination of the lateral lymph nodes in our study, 38 patients showed a positive result and demonstrated LLNM in the final pathological examination $(18.7 \%, 38 / 203)$. Only 3 patients who received fine needle aspiration examination showed an uncertain result such as dysplasia or a blood component in the nonLLNM group $(4.4 \%, 3 / 68)$, which might explain why $25.1 \%(68 / 271)$ of patients did not demonstrate LLNM, making lateral neck dissection unnecessary in these patients. Thus, exhaustive evaluation of the lateral lymph nodes is necessary before the surgery, and aggressive treatment might be avoided especially following fine needle aspiration and TG examination.

In the multivariate analysis, LLNM was significantly associated with ETE $(p=0.026, \mathrm{OR}=2.756,95 \% \mathrm{CI}$ 1.132-6.715), a primary location in the upper pole of the thyroid lobe $(p=0.000, \mathrm{OR}=10.471,95 \%$ CI $4.052-$ $27.062)$ and CLNM ( $\mathrm{p}=0.000, \mathrm{OR}=20.846,95 \% \mathrm{CI}$ 9.505-45.720) with a positive prediction rate of $86.7 \%$. The significant association of LLNM with primary location. This result might be explained by the hypothesis that the carcinoma cells from the upper region are more likely than those from the lower region to be transported to the lateral lymph nodes by lymphatic flow along the superior thyroid artery [22, 37]. Lymph node metastases arising from primary tumor located in the upper portion of the thyroid lobe in patients with CLNM were more frequent in level II than in the other levels. This suggests that the lymphatic drainage system in the upper portion 
Table 4 Univariate analysis results for skip metastasis (203 patients)

\begin{tabular}{|c|c|c|c|c|c|c|}
\hline Characteristics & & Skip negative & Skip positive & Total & Skip rate(\%) & $p$-value \\
\hline \multirow[t]{2}{*}{ Gender } & Female & 128 & 24 & 152 & 15.79 & 0.483 \\
\hline & Male & 45 & 6 & 51 & 11.76 & \\
\hline \multirow[t]{6}{*}{ Age(year) } & $\leq 25$ & 19 & 0 & 19 & 0 & 0.065 \\
\hline & $25-35$ & 36 & 5 & 41 & 12.2 & \\
\hline & $35-45$ & 54 & 10 & 64 & 15.63 & \\
\hline & $45-55$ & 41 & 8 & 49 & 16.33 & \\
\hline & $55-65$ & 13 & 6 & 19 & 31.58 & \\
\hline & $>65$ & 10 & 1 & 11 & 9.09 & \\
\hline \multirow[t]{2}{*}{ Age(year) } & $\leq 45$ & 109 & 15 & 124 & 12.1 & 0.177 \\
\hline & $>45$ & 64 & 15 & 79 & 18.99 & \\
\hline \multirow[t]{5}{*}{ Size(cm) } & $\leq 0.5$ & 4 & 6 & 10 & 60 & $0.001^{*}$ \\
\hline & $0.5-1$ & 39 & 5 & 44 & 11.36 & \\
\hline & $1-1.5$ & 35 & 5 & 40 & 12.5 & \\
\hline & $1.5-2$ & 26 & 6 & 32 & 18.75 & \\
\hline & $>2$ & 69 & 8 & 77 & 10.39 & \\
\hline \multirow[t]{2}{*}{ Tumor Spread } & Absent & 132 & 27 & 159 & 16.98 & 0.147 \\
\hline & Present & 41 & 3 & 44 & 6.82 & \\
\hline \multirow[t]{2}{*}{ Psammoma bodies } & Absent & 166 & 29 & 195 & 14.87 & 1 \\
\hline & Present & 7 & 1 & 8 & 12.5 & \\
\hline \multirow[t]{2}{*}{ Multifocality } & Single & 151 & 28 & 179 & 15.64 & 0.541 \\
\hline & Multi & 22 & 2 & 24 & 8.33 & \\
\hline \multirow[t]{2}{*}{ ETE } & None & 109 & 18 & 127 & 14.17 & 0.753 \\
\hline & ETE & 64 & 12 & 76 & 15.79 & \\
\hline \multirow[t]{4}{*}{ Location } & Upper & 80 & 19 & 99 & 19.19 & 0.387 \\
\hline & Middle & 56 & 7 & 63 & 11.11 & \\
\hline & Inferior & 18 & 2 & 20 & 10.00 & \\
\hline & Whole & 19 & 2 & 21 & 9.52 & \\
\hline \multirow[t]{2}{*}{ Location Upper } & Upper & 80 & 19 & 99 & 19.19 & 0.084 \\
\hline & None & 93 & 11 & 104 & 10.58 & \\
\hline
\end{tabular}

*symbol for $p<0.05$; ETE extrathyroid extension, CLNM central lymph node metastases, LLNM lateral lymph node metastasis

Table 5 Multivariate analysis results for 30 patients with skip metastasis (203 patients)

\begin{tabular}{lllll}
\hline $\begin{array}{l}\text { Predictive } \\
\text { factor }\end{array}$ & $p$ & OR & \multicolumn{2}{l}{ 95\% C.I. of OR } \\
\cline { 5 - 6 } & & & Lower & Upper \\
\hline Size $(>2 \mathrm{~cm})$ & $0.010^{*}$ & & 3.000 & 55.801 \\
Size $(\leq 0.5 \mathrm{~cm})$ & $0.001^{*}$ & 12.937 & 0.338 & 3.614 \\
Size $(0.5-1 \mathrm{~cm})$ & 0.868 & 1.106 & 0.375 & 4.046 \\
Size $(1-1.5 \mathrm{~cm})$ & 0.731 & 1.232 & 0.630 & 6.290 \\
Size $(1.5-2 \mathrm{~cm})$ & 0.241 & 1.990 &
\end{tabular}

*symbol for $p<0.05$; Only predictive factors from the multivariate logistic regression model; $O R$ odds ratio, $\mathrm{Cl}$ confidence interval is different from that in other part of the thyroid lobe [23]. However, several other studies found that location was not significant associated with the pattern of lateral lymph node metastasis [32, 38].

Many previous studies have reported that the dissemination of PTC cells through the lymphatic system occurs in a generally predictable stepwise fashion $[7,8]$.Lymph node metastasis in PTC involves the central compartment first, followed by the ipsilateral lateral compartment and then the contralateral lateral compartment and the mediastinal lymph nodes $[9,10]$. However, some patients have shown LLNM without CLNM, termed skip metastasis, in PTC. The frequency of skip metastasis in PTC is approximately $0.6-37.5 \%$ (Table 6) $[6,8,11-24]$. However, the estimates of frequency come from studies were limited by low patient numbers and the inclusion of primary and recurrent 
Table 6 Summary of previous studies of skip metastasis in PTC (0.6-37.5\%)

\begin{tabular}{|c|c|c|c|c|c|c|c|}
\hline Authors & Year & LLNM Positive & Skip Positive & Skip rate(\%) & Initial Operation & Predictive Factors & Reference \\
\hline Ducci, Appetecchia et al. & 1997 & ND & ND & 11.1 & ND & ND & [11] \\
\hline Coatesworth and MacLennan & 2002 & ND & ND & 37.5 & ND & ND & {$[12]$} \\
\hline Koo, Lim et al. & 2010 & 70 & 12 & 17.1 & Not for All & NA & [13] \\
\hline Machens, Holzhausen et al. & 2004 & 66 & 13 & 19.7 & Not for All & $\begin{array}{l}\text { Fewer Positive } \\
\text { Lymph Nodes }\end{array}$ & {$[8]$} \\
\hline Lee, Wang et al. & 2007 & 46 & 3 & 6.5 & Yes & NA & [14] \\
\hline Roh, Park et al. & 2007 & 22 & 3 & 13.6 & Recurrence & NA & [6] \\
\hline Roh, Kim et al. & 2008 & 52 & 5 & 9.6 & Yes & NA & [15] \\
\hline Wada, Masudo et al. & 2008 & 151 & 17 & 11.3 & Yes & NA & [16] \\
\hline Chung, Kim et al. & 2009 & 12 & 3 & 25 & Yes & NA & [17] \\
\hline Xiao and Gao & 2010 & 64 & 9 & 14.1 & Yes & NA & [18] \\
\hline Kim & 2012 & 490 & 3 & 0.6 & Yes & NA & [19] \\
\hline Kliseska and Makovac & 2012 & 42 & 8 & 19.5 & ND & ND & {$[20]$} \\
\hline Lim and Koo & 2012 & 90 & 17 & 19 & Yes & $\begin{array}{l}\text { Lymphovascular Invasion, } \\
\text { Extracapsular SpreadAnd } \\
\text { fewer Positive Lymph Nodes }\end{array}$ & [21] \\
\hline Park, Lee et al. & 2012 & 147 & 32 & 21.8 & Yes & $\begin{array}{l}\text { Single Focus; Locatedupper; } \\
\text { Microcarcinoma }\end{array}$ & {$[22]$} \\
\hline Lee, Shin et al. & 2014 & 131 & 9 & 6.8 & Yes & Located upper & [23] \\
\hline Xiang, Xie et al. & 2015 & 44 & 11 & 25 & Yes & NA & {$[24]$} \\
\hline
\end{tabular}

NA None analysis; ND No data

patients in their research populations [21]. In this study, a sufficient number of patients (203 patients) underwent simultaneous central and lateral neck dissection for the initial or primary treatment of metastatic PTC. The rate of skip metastasis in the present study was $14.8 \%$, which is range of $0.6 \%$ to $37.5 \%$ based on previous reports $[6,8,11-24]$.

We evaluated the predictive factors of the skip metastasis in PTC. In the univariate analyses, the skip rate was significantly associated only with tumor size, and none of the other predictors. In the multivariate analyses, the skip rate was significantly higher in the small tumor size group (especially with tumor size $\leq 0.5 \mathrm{~cm}$ in diameter) than in the other groups $(p=0.001, \mathrm{OR}=12.937,95 \% \mathrm{CI}$ $3.000-55.801)$. A tumor with a small size $(\leq 0.5 \mathrm{~cm})$ tends to metastasize to the lateral neck without central compartment metastasis. In the present study, if there was a suspicious thyroid node $\leq 0.5 \mathrm{~cm}$ in the US report (like TI-RADS $4 \mathrm{~b}$ or $4 \mathrm{c}$ ), surgery could proceed according to the ATA guideline [39]. As all enrolled patients had suspicious findings for lateral lymph node metastasis preoperative, a total thyroidectomy and neck dissection could proceed in our clinic.

Previous studies have found that skip metastasis is more frequent in less aggressive PTCs such as lowdensity LLNM and microcarcinomas, which is consistent with our findings $[8,21,22]$. In Lim's report, the authors proposed three hypotheses for skip metastasis [21]. However, in the present study, less information was collected on the number of positive lymph nodes and the presence of lympho-vascular invasion; analysis of these variables might help identify the predictive factors for skip metastasis.

In the present study, all patients underwent central compartment dissection (lateral or bilateral according to thyroid lesions), and the skip rate (14.8\%) was much lower than the classical sequential pattern of the LLNM rate $(74.9 \%)$. In the 30 patients who demonstrated skip metastasis, 19 patients had a primary tumor located in the upper part of the thyroid lobe. In the univariate and multivariate analyses, the primary tumor location (upper pole) was not significantly different between the skippositive group and skip-negative group. However, in Lee's report, 9 patients demonstrated skip metastasis, and all primary tumors were located in the upper part of the thyroid lobe. The authors suggested that these results might reflect the nature of the lymphatic drainage system of the thyroid gland, and Park's report showed similar results [22, 23]. In Ito's report, the location of the lesion was significantly associated with the metastasis direction in PTC $[22,37]$. The lymphatic drainage system might explain why skip metastasis frequently occurs in patients whose primary tumors are located in the upper portion of the thyroid lobe. Additionally, only a few studies have reported that the location of the PTC is significantly associated with skip metastasis (Table 6). In the present study, the primary tumor location in the 
upper part of the thyroid lobe was significantly associated with LLNM $(p=0.000, \mathrm{OR}=10.471,95 \% \mathrm{CI}$ 4.052-27.062), similar to other reports [40]. As shown in Table 3, the skip-positive group, the skip-negative group and the total group showed similar distributions of many clinicpathological features, such as gender, age, and primary tumor location. Therefore, although the primary tumor location may serve as a potential predictive factor for skip metastasis, larger multicenter and long-term follow-up studies are necessary to verify these results.

In addition, our study showed that the skip metastasis was not significantly associated with gender, age, tumor spread, presence of psammoma bodies, capsular invasion, ETE or tumor multifocality. Skip metastasis to the lateral neck in PTC patients occurred more frequently in microcarcinoma patients than in other patients, especially those with a primary tumor size less than $0.5 \mathrm{~cm}$ in diameter, which is considered a less aggressive tumor. With only one predictive factor, skip metastasis is difficult to predict and appears to develop in a random fashion.

In the multivariate analysis, tumor intraglandular spread and multifocality were unassociated with LLNM and skip metastasis, similar to some previous reports $[19,21]$. PTC frequently presents with multifocal tumors in up to $80 \%$ of patients [41]; however, there is currently debate over whether tumor multifocality in PTC represents the intraglandular spread of a single tumor or de novo occurrence of distinct tumors. Jovanovic's report showed that among papillary thyroid microcarcinomas with multiple tumor foci, $83 \%$ had genetic alterations consistent with monoclonal origin based on genomewide allelotyping and BRAF mutation analysis. The authors suggested that papillary thyroid microcarcinomas were most often mono-clonally derived and that multiple foci developed through the intraglandular spread of an original tumor. The same conclusion was made in Jung's report; the authors suggest that multifocality might occur during the progression or spread of PTC and represent the intraglandular dissemination of the primary tumor, at least in some cases [42]. It is very difficult to differentiate fully multifocality from intraglandular spread in PTC. The information from the finally result of pathological emanations was employed to classify tumor intraglandular spread and multifocal in the present study.

There are still several potential limitations to this study. This study was limited by its retrospective nature and brief follow-up period. In addition, it investigated only LLNM and skip metastasis. No data were provided regarding other clinicopathological features or long-term follow-up results, such as the numbers of LLNM, other histological subtypes, disease recurrence, postoperative radioiodine studies, thyroglobulin levels, thyroidstimulating hormone levels, and disease-free survival.
We are currently collecting full clinicopathological data and long-term follow-up results for a consecutive report that might be used to improve clinical practice.

\section{Conclusions}

In this study, LLNM was significantly associated with ETE, primary location in the upper pole of the thyroid lobe, and CLNM positive findings; however, skip metastasis was more frequently found in small cancers especially where the primary tumor size was less than $0.5 \mathrm{~cm}$ in diameter. In addition, skip metastasis appeared to develop in a random fashion. Thus, although primary tumor location may serve as a predictive factor for skip metastasis, further research involving larger multicenter and long-term follow-up studies is necessary to verify these results.

\section{Abbreviations \\ ATA: The American Thyroid Association; CLN: Central lymph node; CLNM: Central lymph node metastases; $\mathrm{CN}+$ : Clinical lymph node positive; cNO: Clinical lymph node negative; CT: Computer tomography; ETE: Extrathyroid extension; FNA: Fine needle aspiration cytology; LLN: Lateral lymph node; LLNM: Lateral lymph node metastasis; OR: Odds ratios; PTC: Papillary thyroid carcinoma; SEER: the Surveillance, Epidemiology, and End Results database; SPSS: Statistical Package for Social Sciences; US: Ultrasonic examination or ultrasonography}

\section{Acknowledgements}

The authors would like to thank Prof Minghua Ge for its outstanding assistance and guild in all working stages and thank all patients for their preciously medical records.

\section{Funding}

This research was supported by National Natural Science Foundation of China (No.81550033) and Ministry of Health P. R. China Foundation for Science Research (WKJ2012-2-021).

\section{Availability of data and materials}

The datasets supporting the conclusions of this study are included within the article. Primary data is available upon request from the corresponding author.

\section{Authors' contributions}

XLN has contributed mainly in conducting this research and papering the manuscript. ZT has contributed in research protocol designing and clinical theoretical guiding. MhG has contributed in outstanding assistance and guild in all working stages. All authors read and approved the final manuscript.

\section{Ethics approval and consent to participate}

Institutional review board approval was waived by the responsible Ethics Committee of Zhejiang Cancer Hospital, Hangzhou, PRC, given the

retrospective study design and analysis of clinical data. Patient records and information were anonymized and de-identified prior to analysis in all working stages. For this type of research, a formal consent is not required.

\section{Consent for publication}

Not applicable.

\section{Competing interests}

The authors declare that they have no competing interests.

\section{Publisher's Note}

Springer Nature remains neutral with regard to jurisdictional claims in published maps and institutional affiliations. 
Received: 28 September 2016 Accepted: 19 October 2017 Published online: 25 October 2017

\section{References}

1. Grebe SK, Hay ID. Thyroid cancer nodal metastases: biologic significance and therapeutic considerations. Surg Oncol Clin N Am. 1996;1:43-63.

2. Kupferman ME, Patterson M, Mandel SJ, LiVolsi V, Weber RS. Patterns of lateral neck metastasis in papillary thyroid carcinoma. Arch Otolaryngol Head Neck Surg. 2004;7:857-60

3. Lundgren $\mathrm{Cl}$, Hall P, Dickman PW, Zedenius J. Clinically significant prognostic factors for differentiated thyroid carcinoma: a population-based, nested casecontrol study. Cancer. 2006;3:524-31.

4. McConahey WM, Hay ID, Woolner LB, van Heerden JA, Taylor WF. Papillary thyroid cancer treated at the Mayo Clinic, 1946 through 1970: initial manifestations, pathologic findings, therapy, and outcome. Mayo Clin Proc. 1986;12:978-96

5. Hughes CJ, Shaha AR, Shah JP, Loree TR. Impact of lymph node metastasis in differentiated carcinoma of the thyroid: a matched-pair analysis. Head Neck. 1996;2:127-32

6. Roh JL, Park JY, Rha KS, Park CII. Central neck dissection necessary for the treatment of lateral cervical nodal recurrence of papillary thyroid carcinoma? Head Neck. 2007:10:901-6.

7. Machens A, Hinze R, Thomusch O, Dralle H. Pattern of nodal metastasis for primary and reoperative thyroid cancer. World J Surg. 2002:1:22-8.

8. Machens A, Holzhausen HJ, Dralle H. Skip metastases in thyroid cancer leaping the central lymph node compartment. Arch Surg. 2004;1:43-5.

9. Grodski S, Cornford L, Sywak M, Sidhu S, Delbridge L. Routine level VI lymph node dissection for papillary thyroid cancer: surgical technique. ANZ J Surg. 2007:4:203-8.

10. Goropoulos A, Karamoshos K, Christodoulou A, Ntitsias T, Paulou K, Samaras A, et al. Value of the cervical compartments in the surgical treatment of papillary thyroid carcinoma. World J Surg. 2004;12:1275-81.

11. Ducci M, Appetecchia M, Marzetti M. Neck dissection for surgical treatment of lymphnode metastasis in papillary thyroid carcinoma. J Exp Clin Cancer Res. 1997:3:333-5.

12. Coatesworth AP, MacLennan K. Cervical metastasis in papillary carcinoma of the thyroid: a histopathological study. Int J Clin Pract. 2002:4:241-2.

13. Koo BS, Lim HS, Lim YC, Yoon YH, Kim YM, Park YH, et al. Occult contralateral carcinoma in patients with unilateral papillary thyroid microcarcinoma. Ann Surg Oncol. 2010;4:1101-5.

14. Lee BJ, Wang SG, Lee JC, Son SM, Kim IJ, Kim YK. Level IIb lymph node metastasis in neck dissection for papillary thyroid carcinoma. Arch Otolaryngol Head Neck Surg. 2007;10:1028-30

15. Roh JL, Kim JM, Park Cl. Lateral cervical lymph node metastases from papillary thyroid carcinoma: pattern of nodal metastases and optimal strategy for neck dissection. Ann Surg Oncol. 2008:4:1177-82.

16. Wada N, Masudo K, Nakayama H, Suganuma N, Matsuzu K, Hirakawa S, et al. Clinical outcomes in older or younger patients with papillary thyroid carcinoma: impact of lymphadenopathy and patient age. Eur J Surg Oncol. 2008:2:202-7.

17. Chung YS, Kim JY, Bae JS, Song BJ, Kim JS, Jeon HM, et al. Lateral lymph node metastasis in papillary thyroid carcinoma: results of therapeutic lymph node dissection. Thyroid. 2009:3:241-6.

18. Xiao GZ, Gao L. Central lymph node metastasis: is it a reliable indicator of lateral node involvement in papillary thyroid carcinoma? World J Surg. 2010; 2:237-41.

19. Kim YS. Patterns and predictive factors of lateral lymph node metastasis in papillary thyroid microcarcinoma. Otolaryngol Head Neck Surg. 2012;1:15-9.

20. Kliseska E, Makovac I. Skip metastases in papillary thyroid cancer. Coll Antropol. 2012:59-62.

21. Lim YC, Koo BS. Predictive factors of skip metastases to lateral neck compartment leaping central neck compartment in papillary thyroid carcinoma. Oral Oncol. 2012;3:262-5.

22. Park JH, Lee YS, Kim BW, Chang HS, Park CS. Skip lateral neck node metastases in papillary thyroid carcinoma. World J Surg. 2012:4:743-7.

23. Lee YS, Shin SC, Lim YS, Lee JC, Wang SG, Son SM, et al. Tumor locationdependent skip lateral cervical lymph node metastasis in papillary thyroid cancer. Head Neck. 2014;6:887-91.

24. Xiang D, Xie L, Xu Y, Li Z, Hong Y, Wang P. Papillary thyroid microcarcinomas located at the middle part of the middle third of the thyroid gland correlates with the presence of neck metastasis. Surgery. 2015;3:526-33.
25. Rotstein $L$. The role of lymphadenectomy in the management of papillary carcinoma of the thyroid. J Surg Oncol. 2009:4:186-8.

26. Leboulleux S, Girard E, Rose M, Travagli JP, Sabbah N, Caillou B, et al. Ultrasound criteria of malignancy for cervical lymph nodes in patients followed up for differentiated thyroid cancer. J Clin Endocrinol Metab. 2007;9:3590-4.

27. Som PM, Brandwein M, Lidov M, Lawson W, Biller HF. The varied presentations of papillary thyroid carcinoma cervical nodal disease: CT and MR findings. AJNR Am J Neuroradiol. 1994;6:1123-8.

28. Robbins KT, Clayman G, Levine PA, Medina J, Sessions R, Shaha A, et al. Neck dissection classification update: revisions proposed by the American head and neck society and the American Academy of Otolaryngology-Head and Neck Surgery. Arch Otolaryngol Head Neck Surg. 2002;7:751-8.

29. Edge SB, Compton CC. The American joint committee on cancer: the 7th edition of the AJCC cancer staging manual and the future of TNM. Ann Surg Oncol. 2010;6:1471-4.

30. Sivanandan R, Soo KC. Pattern of cervical lymph node metastases from papillary carcinoma of the thyroid. Br J Surg. 2001;9:1241-4.

31. Machens A, Hofmann C, Hauptmann S, Dralle H. Locoregional recurrence and death from medullary thyroid carcinoma in a contemporaneous series: 5-year results. Eur J Endocrinol. 2007;1:85-93.

32. Wada N, Duh QY, Sugino K, Iwasaki H, Kameyama K, Mimura T, et al. Lymph node metastasis from 259 papillary thyroid microcarcinomas: frequency, pattern of occurrence and recurrence, and optimal strategy for neck dissection. Ann Surg. 2003:3:399-407.

33. Shaha AR. Complications of neck dissection for thyroid cancer. Ann Surg Oncol. 2008:2:397-9.

34. Patron V, Bedfert C, Le Clech G, Aubry K, Jegoux F. Pattern of lateral neck metastases in N0 papillary thyroid carcinoma. BMC Cancer. 2011;8

35. Ali S, Tiwari RM, Snow GB. False-positive and false-negative neck nodes. Head Neck Surg. 1985;2:78-82

36. Kim E, Park JS, Son KR, Kim JH, Jeon SJ, Na DG. Preoperative diagnosis of cervical metastatic lymph nodes in papillary thyroid carcinoma: comparison of ultrasound, computed tomography, and combined ultrasound with computed tomography. Thyroid. 2008;4:411-8

37. Ito Y, Tomoda C, Uruno T, Takamura Y, Miya A, Kobayashi K, et al. Papillary microcarcinoma of the thyroid: how should it be treated? World J Surg. 2004;11:1115-21.

38. Noguchi S, Noguchi A, Murakami N. Papillary carcinoma of the thyroid. I. Developing pattern of metastasis. Cancer. 1970;5:1053-60.

39. Haugen BR, Alexander EK, Bible KC, Doherty GM, Mandel SJ, Nikiforov YE, et al. American Thyroid Association management guidelines for adult patients with thyroid nodules and differentiated thyroid cancer: the American Thyroid Association guidelines task force on thyroid nodules and differentiated thyroid cancer. Thyroid2016. 2015:1:1-133.

40. Lin $\mathrm{KL}$, Wang OC, Zhang XH, Dai XX, Hu XQ, Qu JM. The BRAF mutation is predictive of aggressive clinicopathological characteristics in papillary thyroid microcarcinoma. Ann Surg Oncol. 2010;12:3294-300.

41. Jovanovic L, Delahunt B, Mclver B, Eberhardt NL, Grebe SK. Most multifocal papillary thyroid carcinomas acquire genetic and morphotype diversity through subclonal evolution following the intra-glandular spread of the initial neoplastic clone. J Pathol. 2008;2:145-54.

42. Jung CK, Kang YG, Bae JS, Lim DJ, Choi YJ, Lee KY. Unique patterns of tumor growth related with the risk of lymph node metastasis in papillary thyroid carcinoma. Mod Pathol. 2010;9:1201-8.

\section{Submit your next manuscript to BioMed Central and we will help you at every step:}

- We accept pre-submission inquiries

- Our selector tool helps you to find the most relevant journal

- We provide round the clock customer support

- Convenient online submission

- Thorough peer review

- Inclusion in PubMed and all major indexing services

- Maximum visibility for your research

Submit your manuscript at www.biomedcentral.com/submit 